\title{
Yatırımcı İlgisi İle Pay Piyasası Arasındaki İlişki: BİST-100 Endeksi Üzerine Bir Uygulama ${ }^{1}$
}

\author{
Turhan Korkmaz
}

\author{
Emrah İsmail Çevik ${ }^{b}$
}

\author{
Nüket Kırcı Çevik ${ }^{\mathrm{c}}$
}

Öz: Bilgi, bilgi akışı, bilgi arzı ve bilgi talebi gibi kavramsal terimler finans literatüründe yer alan birçok teorik modelin temelini oluşturmaktadır. Yatırımcıların yatırım kararı alma sürecinde gerek piyasa gerekse firmaya yönelik bilgileri dikkate aldıkları bilinmektedir. Bu açıdan yatırımcı ilgisi ile finansal piyasalar arasındaki ilişki literatürde geniş bir yer bulmuş ve yatırımcı ilgisi doğrudan ölçülemediğinden bu değişken için farklı yaklaşımlar ele alınmıştır. Bu çalışmanın amacı, yatırımcı ilgisi ile pay piyasası arasındaki ilişkiyi ampirik olarak araştırmaktır. Pay piyasasına yönelik yatırıma ilgisini ölçmek için Google arama motorunda aranma sıklığı istatistikleri dikkate alınmıştır. Literatürdeki çalışmalardan farklı olarak, yatırımcı ilgisi ile BIST-100 arasındaki ilişki getiri ve işlem hacmi arasındaki ilişki Hong (2001) tarafindan geliştirilen ortalamada ve varyansta nedensellik testleri kullanılarak araştırılmıştır. Nedensellik testi sonuçları, yatırımcı ilgisinden endeks getirisine yönelik zayıf da olsa bir nedensellik ilişkisi olduğunu göstermektedir. Diğer taraftan, işlem hacmi yatırımcı ilgisinin Granger nedeni olarak bulunmuştur.

Anahtar Sözcükler: Yatırımcı İlgisi, Pay Piyasası, BIST-100, Google Arama Trendleri

JEL Sınıflandırması: G12, C58, F31

\section{The Relationship between Investor Attention and Stock Markets: An Application on ISE-100 Index}

\begin{abstract}
The most of theoretical financial models that have been used in the literature depend on the conceptual terms such as information, information flow, information supply and demand for information. It is well known that investors take into account information about market and company in the process of investment decision. In this context, there have been extensive studies that focus on the relation between investors' relation and financial markets and different proxy variables for measuring investors' relation have been used in the literature due to investors' relation cannot be directly measure. The aim of this study is to examine the empirical relation between investor attention and stock market empirically. In order to determine the investor attention toward stock market, Google search queries statistics are employed. Differently from existing literature, the relationship between investor attention and stock market is analyzed in terms of stock returns and volumes by means of causality in mean and variance test suggested by Hong (2001). Empirical findings suggest weak causal link going from investors' attention to stock returns. On the other hand, stock volume is found to be Granger cause of investors' relation.
\end{abstract}

Keywords: Investors' Relation, Stock Market, BIST 100, Google Search Trends

JEL Classification: G12, C58, F31

aProf., PhD., Mersin University, Faculty of Economics and Administrative Sciences, Department of Business Administration, Mersin, Turkiye, tkorkmaz@mersin.edu.tr

${ }^{b}$ Assoc. Prof., PhD., Namık Kemal University, Faculty of Economics and Administrative Sciences, Department of Economics, Tekirdag, Turkiye, eicevik@nku.edu.tr

'Asst. Prof., PhD., Namık Kemal University, Faculty of Economics and Administrative Sciences, Public Finance Department, Tekirdag, Turkiye,nkcevik@nku.edu.tr 


\section{Giriş}

Finans teorisinin temelini oluşturan birçok model bilginin önemine odaklanmakta ve bilgi akışı, bilgi arzı ve bilgi talebi gibi kavramlar söz konusu modellerde oldukça sık kullanılmaktadır. Etkin piyasalar hipotezine dayanan geleneksel sermaye varlıkları fiyatlama modeli menkul kıymetle ilgili bilgilerin fiyatlara anında ve hızlı bir şekilde yansıdığını varsaymaktadır. Fama (1970) tarafindan önerilen piyasa etkinliği, fiyatlama sürecinde bilginin rolüne vurgu yapmakta ve finansal piyasaların bilgisel etkinliğini ön plana çıkarmaktadır. Benzer şekilde, Karışık Dağıım Hipotezine (Mixture Distribution Hypothesis) göre, finansal piyasalardaki oynaklık veya işlem hacminin bilgi akışı ile doğrudan ilişkili olduğu vurgulanmaktadır. Bununla birlikte söz konusu modellerin altında yatan temel varsayım, yatırımcıların piyasaya gelen tüm bilgilere aynı anda ulaştğıdır. Ancak bu durum gerçek hayatta her zaman geçerli olmamakta ve yatırımcıların bir kısmı sınırlı bilgiye sahip olabilmektedir. Piyasalarda tüm yatırımcıların her bilgiye eşanlı olarak ulaşamaması durumu finans literatüründe asimetrik bilgi teorisi ile açıklanmaktadır. Yatırımcıların sınırsız bilgiye sahip olabilmesi için sermaye piyasalarında yer alan firmalar hakkındaki tüm gelişmeleri yakından takip etmiş olmaları gerekmektedir. Davranışsal finans alanında çalışmalarda bulunan Kahneman (1973), yatırımcı ilgisinin az bulunur algısal bir aktivite olduğunu belirtmiş ve buna bağlı olarak bireysel yatırımcıların sermaye piyasalarındaki tüm gelişmeleri yakından takip etmesinin çok kolay bir durum olmadığını belirtmiştir. Davranışsal finans alanında özellikle son yıllarda gerçekleştirilen çalışmalar, piyasaya ulaşan herhangi bir yeni bilgi olmasa dahi kamuoyu ilgisinin pay fiyatlarını hareketlendirmek için tek başına yeterli olduğunu göstermiş̧tir (Da, Engelberg ve Gao, 2011).

Merton (1987) tarafindan geliştirilen "yatırımcı tanınmışlık hipotezine" göre, yatırımcıların yeterli bilgi sahibi olmadan sadece farkında oldukları paya yatrım yaptikları varsayılmaktadır. Barber ve Odean (2008) tarafindan geliştirilen "dikkat teorisi" ise, bireysel yatırımcıların genelde dikkatlerini (ya da ilgilerini) çeken payları satın almaya meyilli olduklarını öne sürmektedir. Buna gerekçe olarak da, bireysel yatırımcıların yüzlerce firmayı analiz etmek veya araştırmak için yeterince zamana sahip olmadıkları belirtilmektedir. Bu nedenle, yatırımcılar genelde karar verirken yüzlerce firma arasından dikkatini çeken firmalara yatırım yapmayı tercih etmektedir. Sonuç olarak, yatırımcı ilgisinin (yatırım yapılacak firmaya ilişkin araştırma yapmak) artmasının aşırı yüksek getiri ve işılem hacmi yarattı̆ı belirtilmiştir (Da vd., 2011).

$\mathrm{Bu}$ açıdan yatırımcı ilgisi ile finansal piyasalar arasındaki ilişki literatürde geniş bir yer bulmuş ve yatırımcı ilgisi doğrudan ölçülemediğinden farklı yaklaşımlar ele alınmıştır. Örneğin, Barber ve Odean (2008) yatırımcı ilgisini ölçmek için aşırı getirileri (excess returns) ve işlem hacmini dikkate alırken, Gervais, Kaniel ve Mingelgrin (2001) ve Hou, Peng ve Xiong (2008) işlem hacmini ve Seasholes ve Wu (2007) fiyat limitlerini kullanmışlardır. Yatıııcı ilgisini ölçebilmek için kullanılan bir diğer değişken ise firmalara ait reklamlar ve reklam harcamalarıdır (Grullon, Kanatas ve Weston (2004); Lou (2008); Fehle, Tsyplakov ve Zdorovtsov (2005); Takeda ve Yamazaki (2006); DellaVigna ve Pollet (2009) ve Chemmanur ve Yan (2009)). Bununla birlikte yatırımcı ilgisini ölçmek için kullanılan söz konusu değişkenler pay getirisi aşırı olursa veya işlem hacmi yüksek olursa yatıııcıların söz konusu menkul kıymete daha fazla ilgi gösterdiği gibi temel bir varsayıma dayanmaktadır. Diğer taraftan, getiri veya işlem hacmi yatırımcı ilgisinden alakasız faktörlerden kaynaklanabilir veya yatırımcılar firmalarla ilgili medyada yer alan haberleri okumamış olabilir. Bu durum özellikle bilgi çağı olarak adlandırılan ve "çok sayıda bilginin düşük düzeyde ilgiyi beraberinde getirdiği" görüşünü doğrulamaktadır.

Son yıllarda yapılan ampirik çalışmalar, Google arama motorundan elde edilen arama sonuçlarının yatırımcı ilgisini ölçmek için uygun bir değişken olduğu yönündedir. Google firması 2004 yılından itibaren Google Arama Trendleri (GAT) adı altında arama motorunda aranan terimlerinin sıklığına ulaşılabilme imkanı sağlamıştır. Google, arama verilerinin karşılaştrıımasını kolaylaştırmak için GAT'daki sonuçları normalleştirerek vermektedir. Normalleştirme işlemi herhangi bir kelimenin güncel aranma sayısı ile toplam aranma sayısına göre yapılmaktadır. Daha sonra, normalleştirilen arama sayısı en yüksek çevrimiçi arama seviyesine göre yeniden ölçeklendirilmektedir. Söz konusu ölçeklendirme yöntemi aranan kelime için 0 ile 100 aralığında değişen bir veri sunmaktadır. Son olarak GAT herhangi bir kelimenin hangi sıkıkla arandığına dair haftalık istatistikler sağlamaktadır. 
Kuşkusuz bu noktada dikkat edilmesi gereken nokta insanların ne sıklıkta internet kullandıkları ve internet üzerinde araşttrma yaparken hangi arama motorunu tercih ettikleridir. Bu doğrultuda Türkiye'deki kullanıcıların yüksek bir düzeyde Google'ı tercih etmeleri yatırımcı ilgisi için daha sağlıklı veri temin edileceğini göstermektedir. Yatıımcıların bir kısmının ulaşmak istedikleri bilgiyi Google arama motoru kullanarak elde ettikleri varsayılmaktadır. 2015 yılı Aralık ayı verilerine göre, Türkiye'de internet kullanım oranı $\% 60^{2}$ ve Google arama motorunu kullanım oranı $\% 95^{3}$ şeklinde ölçülmüştür. Söz konusu rakamlar Türkiye'de yaşayan bireylerin bilgi edinme konusunda interneti ve Google arama motorunu azımsanmayacak derecede kullandığının bir göstergesidir. Bu durum ise, yatırımcı ilgisi için Google arama motorundan elde edilen istatistiklerin önemli bir gösterge olabileceğini ifade etmektedir.

Dzielinski (2012) uygulamalı analizlerde GAT verilerini kullanmanın iki önemli avantajı olduğunu belirtmiştir. Illk olarak GAT 2004 yılından itibaren haftalık veriler sunmaktadır ve anket verileri ile karşılaştırıldığında (örneğin tüketici güvenini ölçmek için gibi) daha yüksek frekanslı veri elde edilmesine olanak sağlamaktadır. Ikincisi ise verilerin finansal piyasalardaki gelişmelerden bağımsız bir şeklide kendiliğinden (spontane) ortaya çıkması ile ilgilidir ve bu durum ekonometrik analizlerde yer alan tahmin konusunda en büyük soruna yol açan içsellik sorununu ortadan kaldırmaktadır. Bununla birlikte, anket verileri ile karşılaştırıldığında GAT yakın bir gelecek için neredeyse anlık veriler türetmekte ve bu durum özellikle geleceği öngörmek için büyük bir önem arz etmektedir.

Bu çalışmada, yatırımcı ilgisi ile Borsa İstanbul 100 endeksi arasındaki nedensellik ilişkisi araştrılıcaktır. Literatürde Borsa İstanbul özelinde GAT verilerini kullanarak yatırımcı ilgisini ölçen bir çalışma hali hazırda mevcut değildir. Bu açıdan söz konusu çalışmanın literatüre önemli bir katkı sağlayacağı düşünülmektedir. Çalışma beş bölümden oluşmaktadır. İkinci bölümde literatürde yer alan çalışmalara yer verildikten sonra üçüncü bölümde çalışmada kullanılan ekonometrik modeller tanıtılacaktır. Dördüncü bölümde analiz sonuçlarına yer verilecek ve son bölümde elde edilen sonuçlar genel olarak değerlendirilecektir.

\section{Literatür Özeti}

Literatürde ekonomideki farklı alanlar için GAT verilerini kullanan çok sayıda çalışma bulunmaktadır. Finans alanında GAT tarafindan sağlanan verileri kullanan ilk çalışma Mondria, Wu ve Zhang (2010) tarafindan gerçekleştirilmiş ve söz konusu çalışmada uluslararası portföy çeşitlendirmesinin faydalarına rağmen, yatıııcıların sadece kendi ülkelerindeki paylara yatırım yapma eğilimleri (home bias) hipotezinin geçerliliği ampirik olarak araştırılmıştır. Literatürde yatırımcı ilgisini GAT verilerini kullanarak araştıran ilk çalışma ise Da vd. (2011) tarafindan yapılmıştır. Da vd. (2011) yatırımcı ilgisinin ölçümü olarak GAT verilerini kullanmanın birçok avantajı olabileceğini belirtmiştir. Örneğin, internet kullanıcılarının genelde arama motoru olarak Google kullandıklarını ve bu nedenle GAT tarafindan sağlanan verilerin genel nüfusun internette araştırma davranışlarını gösterdiğini belirtmiştir. Buna ek olarak, arama motorunda aranan kelimelerin açığa çıkan bir ilginin ölçümü olduğu (örneğin Google'da bir paya ilişkin araştrrma yapılıyorsa söz konusu paya bir ilgi gösterildiği varsayılmaktadır) yönündedir. Bu nedenle Da vd. (2011) Google'da gerçekleştirilen arama sıklığının söz konusu konuya ilginin doğrudan ve kesin bir ölçümü olacağını belirtmiştir. Da vd. (2011) yatırımcı ilgisini ölçmek için ABD sermaye piyasasında işlem gören firmaların pay piyasası kodlarının Google arama motorunda aranma sıklıklarını dikkate almıştır. 2004-2008 yılları arasında GAT'tan elde ettikleri değişkenin yatırımcı ilgisini ölçmek için kullanılan diğer değişkenler (örneğin, işlem hacmi, aşırı getiri, medyada yer alan haberler ve reklam harcamaları gibi) ile ilişkili olduğunu belirlemişlerdir. Barber ve Odean (2008) tarafindan önerilen fiyat baskı hipotezini ampirik olarak test etmişler ve analiz sonucunda firmaların internet üzerinde aranma sıklığı artıkça iki hafta için fiyatların yükseldiği fakat bir yılsonunda bu durumun tersine döndüğünü belirlemişlerdir.

Joseph, Babajide ve Zhang (2011) S\&P500'te yer alan firmaların pay piyasası kodlarının internet üzerinde aranma sıklığı ile aşırı getiri ve işlem hacmini öngörmede daha iyi sonuçlar verip vermediğini 20052008 dönemi için araştırmışlardır. Bu bağlamda firmaların pay piyasası kodlarının Google arama motorunda aranmasının yatırımcı ilgisi ile yakından ilişkili olduğu belirlenmiştir. Çalışmada, firmalar internet üzerinde arama yoğunluklarına göre farklı portföylere ayrılmış ve firmaların internette aranma sıklığının kısa dönemde 
getiri üzerinde pozitif bir etki yarattı̆ı, fakat orta ve uzun dönemde söz konusu ilişkinin tersine döndüğü sonucuna ulaşılmıştır.

Bank, Larch ve Peter (2011) 2004 ile 2010 yılları arasında Almanya'da yatırımcıların firmaya olan ilgisi ile pay piyasasındaki işlem hacmi arasındaki ilişkiyi araştırmıştır. Yatırımcıların firmalara olan ilgisini ölçmek için Google arama motorunda firma adını yazarak yapılan aramalar ele alınmıştır. Analizler sonucunda, firma isminin arama motorunda aranma sıklığı ile pay piyasasındaki işlem hacmi arasında anlamlı bir ilişki tespit edilmiştir. Buna ilave olarak, firmanın isminin internette aranma sıklığı ile likidite arasında ters yönlü bir ilişkinin olduğunu belirlemişlerdir ve söz konusu ilişkinin varlığını asimetrik bilginin maliyetindeki değişime bağlamışlardır. Kısa dönemde firma isminin aranma sıklığı ile pay getirisi arasında pozitif bir ilişkinin varlığı tespit edilmiştir. Bulgulara göre, firmaların internette aranma sayısı asimetrik bilginin azalmasına, likiditenin artmasına ve kısa dönemli pay alımlarının artmasına neden olmaktadır.

Latoeiro vd. (2013) EURO STOXX 50 endeksinde işlem gören firmaların internette aranma sıklığı ile yatırım kararları arasında bir ilişki olup olmadığını araştırmıştı. Firma isimlerinin internette aranma sıklığı arttğında finansal piyasalarda işlem hacmi ve oynaklığın arttı̆ı ve bu etkinin ise bir hafta gibi kısa süreli olduğu belirlenmiştir. Aouadi vd. (2013) yatırımcıların firmaya olan ilgisi ile likidite ve oynaklık arasındaki ilişkiyi 20042010 dönemi için incelemişlerdir. Yatırımcıların firmaya olan ilgisini ölçebilmek için Google arama motoru verilerini kullanmışlardır. Analiz sonucunda Fransa Menkul Kıymetler Borsası'nda işlem gören firmaların internette aranma sıklığı ile payın likiditesi ve oynaklığı arasında anlamlı bir ilişki olduğu bulunmuştur.

Takeda ve Wakao (2014) Japonya borsasında işlem gören firmaların internette aranma sıklığı ile payın getirisi ve işlem hacmi arasındaki ilişkiyi yatırımcı ilgisi hipotezine göre incelemişlerdir. Google arama motor verilerini kullanarak Nikkei 225 içinde yer alan 189 şirketi dikkate almışlardır. Analiz sonuçlarına göre, firmaların internette aranma sıklığı ile payın fiyatı ve işlem hacmi arasında pozitif yönlü bir ilişki belirlenmiş fakat firmaların internette aranma sıkığının artmasının işlem hacmini fiyata göre daha fazla arttırdığı sonucuna ulaşmışlardır.

Literatürde Google arama motoru verilerini kullanarak yatırımcı algısı ile genel borsa endeksi ve döviz kurları arasındaki ilişkiyi araştıran çalışmalar da mevcuttur. Örneğin, Beer, Hervé ve Zouaoui (2012) Google arama motoru verilerini kullanarak Fransa için yatırımcı algısını ölçmeye çalışmıştır. Yatırımcıların piyasaya yönelik kötümser bakış açılarını ölçmek için Google arama motorunda "ekonomi" ve "negatif" kelimelerinin aranma sıklı̆ını dikkate almışlardır. Söz konusu kelimelere göre elde ettikleri değişkenin literatürde yer alan diğer algı değişkenleri ile ilişkili olduğunu ve yatırımcı algısının finansal piyasalarda fon yatırımcılarının davranışlarını değiştirdiğini belirlemişlerdir. Özellikle kısa dönemde yatırımcı algısının payın getirisini öngörmede başarılı sonuçlar verdiğini belirlemişlerdir.

Smith (2012) "ekonomik kriz", "finansal kriz", "resesyon" ve "enflasyon" kelimelerinin internette aranma sıklığı ile döviz kurlarının oynaklığı arasındaki ilişkiyi analiz etmiştir. Yedi gelişmiş ülkenin döviz kurlarının kullanıldığı çalışmada iki aşamalı bir yöntem izlemiştir. İlk aşamada, her bir döviz kuru serisi için GARCH model ile koşullu oynaklık tahmin edilmiş, ikinci aşamada ise söz konusu kelimelerin arama sıklığı ile oynaklık arasındaki ilişki EKK yöntemi kullanılarak araştrılmıştı. Analiz sonuçlarına göre, "ekonomik kriz", "finansal kriz" ve "resesyon" kelimelerinin aranma sıklığının kurlardaki oynaklığı tahmin etmede anlamlı sonuç verdiğini belirlemiştir.

Dzielinski (2012) ABD ekonomisinde ekonomik belirsizliği ölçebilmek için GAT verilerini dikkate almıştır. Google arama motorunda "ekonomi" kelimesinin aranma sıklığını ekonomik belirsizliğin bir ölçütü olarak ele aldığında söz konusu ölçümün literatürde kullanılan diğer alternatif ölçümler ile benzer sonuçlar verdiğini ve endeks getirisi ile oynaklık üzerinde anlamlı bir etkiye sahip olduğunu belirlemiştir.

Liu, Peng ve Zhang (2012) Çin menkul kıymetler borsasında internet arama verisi ile borsa endeksi arasındaki ilişkiyi araştırmışlardır. Bu bağlamda yatırımcı endeksi, piyasa durum endeksi ve makroekonomik endeks olmak üzere üç endeks oluşturmuşlardır. Granger nedensellik testi söz konusu endekslerin Çin Menkul Kıymetler Borsası'nda yıllık getiriyi öngörmede başarılı sonuçlar verdiği ve söz konusu üç endeksteki artş̧ın yıllık getiriyi pozitif yönde etkilediği sonucuna ulaşmışlardır. 


\section{Ekonometrik Model}

Çalışmada, yatırımcı ilgisi ile Borsa İstanbul 100 (BIST100) endeks getirisi ve işlem hacmi arasındaki dinamik ilişki Vektör Otoregresif (VAR) modele dayalı Granger nedensellik testi ve Hong (2001) tarafindan geliştirilen ortalama ve varyansta nedensellik testleri ile araştırılacaktır.

VAR modeli kullanmanın en önemli avantajı değişkenlere yönelik içsel ya da dışsal gibi ön bir varsayımının yapılmamasıdır. Çünkü VAR modelde tüm değişkenler içsel olarak ele alınmaktadır ve her bir değişken sistemdeki tüm değişkenlerin geçmiş değerlerine bağlı olarak belirlenmektedir (Henriques ve Sadorsky, 2008:1000). VAR modelinin matematiksel model formu aşağıdaki gibidir:

$$
y_{t}=A_{1} y_{t-1}+\cdots+A_{p} y_{t-p}+B x_{t}+\varepsilon_{t}
$$

burada, $y_{t}$ içsel değişkenler vektörü, $x_{t}$ dışsal değişkenler vektörü, $A_{1}, \ldots, A_{p}$ ve $B$ tahmin edilen katsayılar matrisi ve $\varepsilon_{\mathrm{t}}$ sağ taraf değişkenleriyle ilişkisiz seri korelasyonsuz hata terimlerini ifade etmektedir.

VAR modelde parametrelerin doğrudan yorumu pek anlamlı olmamaktadır. Bu nedenle, etki-tepki (impulse-response) ve varyans ayrıştırması analizleri yapılarak birtakım yorumlarda bulunulmaktadır. Bunun sonucunda, sistemdeki değişkenlerin kendi veya başka değişkenlerin şoklarına karşı gösterdiği tepkiler önemli olmaktadır. Zaman serisi modellerinde, hata terimleri genelde şokları temsil etmek için kullanılmaktadır. Bunun sonucu sistemdeki her bir değişkenin kendi ve diğer değişkenlerin hatalarına karşı reaksiyonu etkitepkiler olarak adlandırılır. Etki-tepkiler aynı büyüklüğün iki farklı görünümünü ifade eder. Şoku veren değişken yönünden etki, şoku alan değişken yönündense tepki söz konusudur. íki değişken arasında değişkenlerden birinin diğerine neden olduğu yargılamasına dayalı olarak yapılan bu analiz "etki-tepki" analizi olarak adlandırılır (Tarı, 2006:435).

Bununla birlikte, geleneksel Granger nedensellik testi, hata terimlerinin normal dağılması, otokorelasyonsuz ve sabit varyanslı olması gibi bazı varsayımlara dayanmaktadır. Diğer taraftan, özellikle finansal getiri serilerinin normal dağılmadığı ve koşullu değişen varyans özelliği sergilediği bilinmekte ve bu nedenle finansal getiri serileri ile yapılan geleneksel nedensellik testleri sapmalı sonuçlar verebilmektedir. Buna ilaveten, geleneksel nedensellik testleri sadece serilerin birinci momentindeki nedensellik ilişkisini incelerken, özellikle finansal seriler için oynaklıkta ya da varyansta nedensellik ilişkisi de, oynaklıkta yayılma ilişkisini araştrırken büyük önem arz etmektedir. Bu açıdan Mantalos ve Shukur (2010) Monte Carlo simülasyon çalışmalarına dayandırarak, finansal değişkenler arasında oynaklık yayılma etkisinin var olduğu durumda nedensellik yoktur sıfir hipotezinin reddedilme olasılığının anlamlı derecede arttğı sonucuna ulaşmıştr. Ayrıca Cheung ve Ng (1996) serilerin varyansındaki değişimin bilgi hızıyla ilişkili olduğunu ve piyasaya yeni gelen bilginin ne kadar hızlı yayıldı̆̆ını gösterdiğini belirtmiştir. Cheung ve Ng (1996) tarafindan geliştirilen ve daha sonrasında Hong (2001) tarafindan modifiye edilen ortalama ve varyansta nedensellik testi serilerin normal dağılmadığı ve koşullu değişen varyans özelliği gösterdiği durumlarda daha iyi sonuçlar vermektedir. Çünkü bu test yönteminde öncelikle seriler GARCH model ile tahmin edilirken serilerin dağılım özellikleri dikkate alınmaktadır.

Hong (2001) tarafindan önerilen varyansta nedensellik testi iki aşamadan oluşmakta ve ilk aşamada her bir seri için tek değişkenli GARCH modellerin tahmin edilmesi gerekmektedir. Bu bakımdan çalışma kapsamında pay getiri serisi Nelson (1991) tarafindan geliştirilen EGARCH modeli ile işlem hacmi ve yatırımcı ilgisi serisi Bollerslev (1986) tarafindan geliştirilen GARCH ile tahmin edilmiştir. ${ }^{4}$

Endeks getirisi (ya da işlem hacmi) (BIST $T_{t}$ ) ve yatrımcı ilgisi $\left(Y I_{t}\right)(E) G A R C H(1,1)$ süreci izleyen iki durağan ve ergodik zaman serisi şeklinde aşağıdaki gibi tanımlanırsa: 


$$
\begin{aligned}
& B I S T_{t}=\mu_{B I S T, t}+\varepsilon_{t}, \\
& \varepsilon_{t} \backslash\left(\varepsilon_{t-1}, \varepsilon_{t-2}, \ldots, B I S T_{t-1}, B I S T_{t-2}, \ldots\right) \sim \operatorname{GED}\left(0, h_{B I S T, t}\right) \\
& h_{B I S T, t}=\omega_{B I S T}+\alpha_{B I S T}\left|\frac{\varepsilon_{t-1}}{\sqrt{h_{B I S T, t-1}}}\right|+\beta_{B I S T} h_{B I S T, t-1}+\gamma \frac{\varepsilon_{t-1}}{\sqrt{h_{B I S T, t-1}}} \\
& Y i_{t}=\mu_{Y i, t}+\zeta_{t}, \\
& \zeta_{t} \backslash\left(\zeta_{t-1}, \zeta_{t-2}, \ldots, Y i_{t-1}, Y i_{t-2}, \ldots\right) \sim G E D\left(0, h_{Y i, t}\right) \\
& h_{Y i, t}=\omega_{r}+\alpha_{Y i} \zeta_{t-1}^{2}+\beta_{Y i} h_{Y i, t-1}
\end{aligned}
$$

burada $\mu_{B I S T, t}$ ve $\mu_{Y i, t}$ ile $\varepsilon_{t}$ ve $\zeta_{t}$ getiri (işlem hacmi) ve yatırımcı ilgisi serileri için ortalamayı ve hata terimlerini göstermektedir.

$I_{t}$ ve $J_{t}$ iki bilgi seti olarak tanımlanırsa $I_{t}=\left\{B I S T_{t-j} ; j \geq 0\right\}$ ve $J_{t}=\left\{B I S T_{t-j}, Y I_{t-j} ; j \geq 0\right\}$ ve eğer aşağıdaki eşitsizlik gerçekleşirse, yatırımcı ilgisi pay getirisinin varyansta nedenidir denir:

$$
E\left\{\left(B I S T_{t+1}-\mu_{v i, t+1}\right)^{2} \mid I_{t}\right\} \neq E\left\{\left(B I S T_{t+1}-\mu_{B I S T, t+1}\right)^{2} \mid J_{t}\right\}
$$

Denklem (4) Cheung ve Ng (1996) tarafindan tanımlanan varyansta nedensellik ilişkisini gösterir. Bu testi uygulamak için, Denklem (2) ve Denklem (3)'den elde edilen standardize hataların kareleri şu şekilde hesaplanır:

$u_{t}=\left\{\left(B I S T_{t}-\mu_{B I S T, t}\right)^{2} / h_{B I S T, t}\right\}=\varepsilon_{t}^{2}$ ve $v_{t}=\left\{\left(Y i_{t}-\mu_{Y i, t}\right)^{2} / h_{Y i, t}\right\}=\zeta_{t}^{2}$.

Değişkenler arasındaki nedensellik ilişkisini belirleyebilmek amacıyla Hong (2001) tarafindan önerilen $Q$ test istatistiği belirli bir gecikme sayısı $(M)$ için aşağıdaki gibi hesaplanır:

$$
Q=\frac{T \sum_{l=1}^{T-1} k^{2}\left(\frac{I}{M}\right) \hat{\rho}_{u v}^{2}(I)-C_{1 T}(k)}{\sqrt{2 D_{1 T}(k)}}
$$

Denklem (5)'te $\hat{\rho}_{u v}^{2}(I)$ I. gecikme için örnek çapraz korelasyonu göstermekte ve şu şekilde hesaplanmaktadır: $\hat{\rho}_{u v}^{2}(I)=\left\{\hat{C}_{u u}(0) \hat{C}_{v v}(0)\right\}^{-1 / 2} \hat{C}_{u v}(I)$, burada örnek çapraz kovaryans fonksiyonu aşağıdaki gibi hesaplanır: $\hat{C}_{u v}(I)= \begin{cases}T^{-1} \sum_{t=I+1}^{T} \hat{u}_{t} \hat{v}_{t-l}, & I \geq 0 \\ T^{-1} \sum_{t=-l+1}^{T} \hat{u}_{t+l} \hat{v}_{t}, & I<0\end{cases}$ burada $\hat{C}_{u u}(0)=T^{-1} \sum_{t=1}^{T} \hat{u}_{t}^{2}, \hat{C}_{v v}(0)=T^{-1} \sum_{t=1}^{T} \hat{v}_{t}^{2}$ şeklindedir. $\hat{u}_{t}$ ve $\hat{v}_{t}$ GARCH modelden elde edilen karesi alınmış standardize hatalardır. Ayrıca $k(I / M)$ Bartlett kernel olarak aşağıdaki gibi tanımlanan bir ağırlık fonksiyonudur: 


$$
k(I / M)=\left\{\begin{array}{cc}
1-|l /(M+1)| & \text { eğer } k /(M+1) \leq 1 \\
0 & \text { diğer durumlarda }
\end{array}\right.
$$

burada $C_{1 T}(k)=\sum_{l=1}^{T-1}(1-|I| / T) k^{2}(I / M)$ ve $D_{1 T}(k)=\sum_{l=1}^{T-1}(1-|I| / T)\{1-(|l|+1) / T\} k^{4}(I / M)$

Hong (2001) test yönteminin aşamalarını şu şekilde tanımlamıştır:

1. Zaman serileri için tek değişkenli $\operatorname{GARCH}(p, q)$ modeli tahmin edilir ve standardize edilmiş hata terimleri belirlenir.

2. Standardize edilmiş hatalar arasındaki örnek çapraz korelasyon fonksiyonu $\hat{\rho}_{u v}(l)$ hesaplanır.

3. Spesifik gecikme sayısı $M$ belirlenir ve $C_{1 T}(k)$ ile $D_{1 T}(k)$ fonksiyonları hesaplanır.

4. $Q$ test istatistiğini hesaplanır ve belirli bir önem düzeyinde normal dağılım için sağ taraf kritik değer ile karşılaştırılır. Eğer $Q$ istatistiği kritik tablo değerinden daha büyükse, nedensellik yoktur sıfir hipotezini reddedilir. Test yönteminde sıfir hipotezi ret bölgesi normal dağılımın sağ kuyruğunda yer aldığından, \%5 önem düzeyindeki tablo değeri 1.645'tir.

\section{Veri ve Analiz Sonuçları}

Bu çalışmada bireysel yatıımcıların pay piyasasına olan ilgisi ile payın getirisi, işlem hacmi ve oynaklığı arasındaki ilişki araştırılmıştır. Çalışmada 2004 ile 2016 yılları arasındaki haftalık veriler kullanılmıştır. Çalışmanın 2004 yılından başlaması ve haftalık veriler kullanılmasının temel nedeni GAT verilerine 2004 yılından itibaren ve haftalık olarak ulaşılabilmesidir. Çalışmada, pay olarak Borsa İstanbul 100 endeksi kullanılmıştır. Yatırımcı ilgisi için Google arama motorunda Borsa İstanbul ile aramalar dikkate alınmıştır. Bu amaçla "Borsa İstanbul" "Borsa" "IMKB" ve "BIST" kelimelerinin aranma sıklıklarının toplamı hesaplanarak yatıımcı ilgisi belirlenmiştir. ${ }^{5}$ Borsa İstanbul 100 endeksi kapanış fiyatları ve işlem hacmi TCMB elektronik veri dağıtım sisteminden temin edilmiştir. Getiri serisi BIST-100 kapanış fiyatlarının logaritmik farkı alınarak hesaplanmıştır. Yatırımcı ilgisi ve işlem hacmi serilerinin doğal logaritmaları analizlerde kullanılmıştır.

Tablo 1'de değişkenlere ait tanımlayııı istatistikler yer almaktadır. Tablo 1'deki verilere göre, çarpıklık ve basıklık değerleri serilerin dağılımının normal dağılımdan uzaklaştı̆ını göstermekte ve Jarque-Bera test istatistiği de bu sonucu doğrulamaktadır. ARCH testi sonucuna göre, tüm seriler koşullu değişen varyans özelliği göstermekte, serilerin kendisi ve karesi için Ljung-Box istatistikleri serilerde yüksek düzeyde otokorelasyon olduğunu belirtmektedir. ADF ve PP birim kök test sonuçlarına göre seriler düzey değerlerde durağan bulunmuştur.

Tablo 1. Tanımlayııı İstatistikler

\begin{tabular}{l|c|c|c}
\hline & LYi & BIST & LiH \\
\hline $\mathrm{N}$ & 646 & 646 & 646 \\
Ortalama & 4.014 & 0.217 & 16.049 \\
Std. Sapma & 0.173 & 3.778 & 0.617 \\
Çarpıklık & 0.467 & -0.381 & -0.645 \\
Basıklık & 5.082 & 4.904 & 3.557 \\
Jarque-Bera & $140.32[0.000]$ & $113.29[0.000]$ & $53.184[0.000]$ \\
ARCH (5) & $397.98[0.000]$ & $11.893[0.000]$ & $285.26[0.000]$ \\
Q (10) & $2990.55[0.000]$ & $11.202[0.000]$ & $3160.86[0.000]$ \\
Qs (10) & $2899.46[0.000]$ & $126.877[0.000]$ & $3278.92[0.000]$ \\
ADF & $-5.147^{* * *}$ & $-25.873^{* * *}$ & $-9.341^{* * *}$ \\
PP & $-6.091^{* * *}$ & $-25.901 * * *$ & $-20.864 * * *$ \\
\hline
\end{tabular}

Not: Parantez içindeki değerler sıfır hipotezi reddedebilmek için olasılık değerini göstermektedir. ARCH(5) koşullu varyans için LM testi sonucunu ve $Q(10)$ ve $Q_{s}(10)$ seriler ve serilerin kareleri için Ljung-Box otokorelasyon test sonuçlarını göstermektedir. ${ }^{* * *}$ işareti serinin \%1 anlamlılık düzeyinde durağan olduğunu belirtmektedir. LYi ve LiH sırasıyla yatırımcı ilgisi ve işlem hacmi değişkenlerini göstermekte olup değişkenlerin başındaki L harfi ilgili değişkenin doğal logaritmasını göstermektedir. 
Şekil 1'de GAT verileri kullanılarak elde edilen yatırımcı ilgisi değişkeni ve BIST-100 endeksi için getiri ve işlem hacmi serileri yer almaktadır. Özellikle kriz dönemlerinde (2006 yılında finansal piyasalarda yaşanan türbülans, 2007-2008 küresel finansal kriz, 2011-2012 Avrupa borç krizi gibi) yatırımcıların paylara olan ilgisi ve Borsa İstanbul'un GAT'ta aranma sıklığı gözle görülür bir şekilde artmaktadır.

Şekil 1. BIST-100 Getiri ve İşlem Hacmi ile Borsa İstanbul'un İnternette Aranma Sıklığı

BIST-100 GETiRi

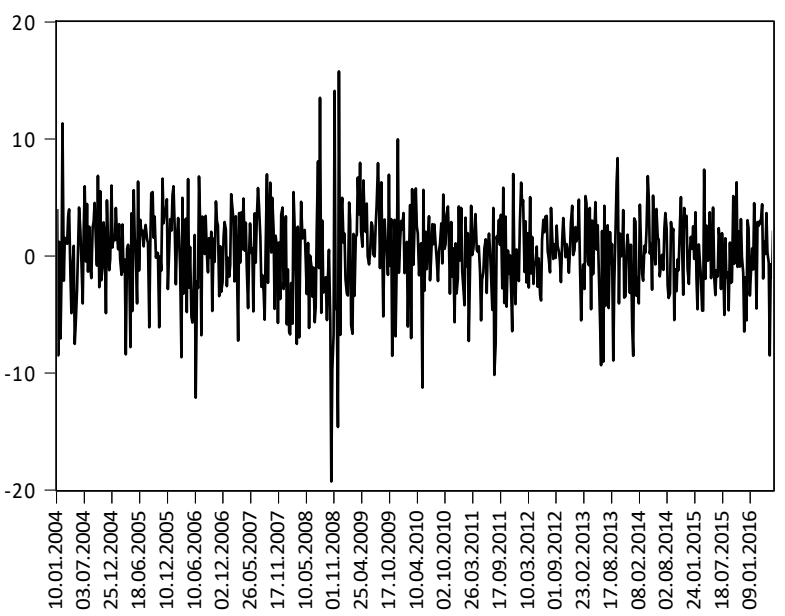

YATIRIMCI iLGISi

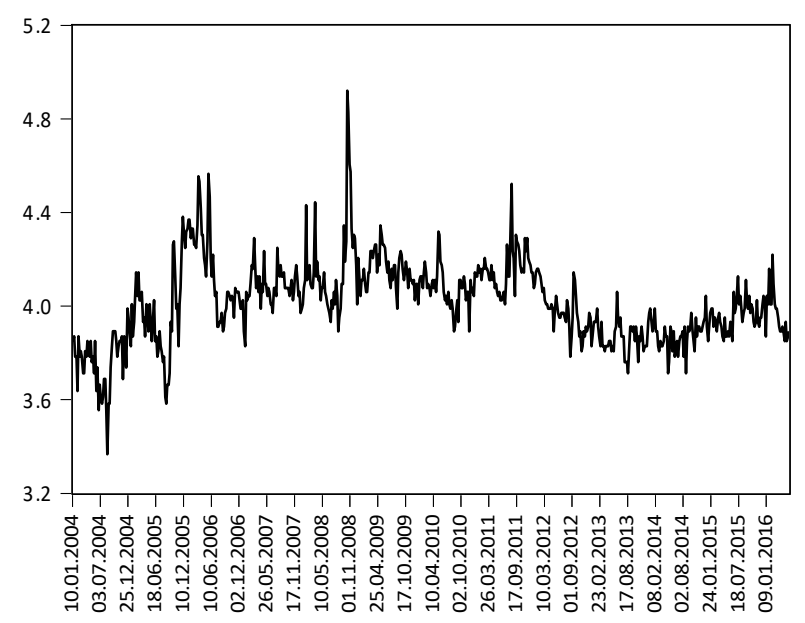

LN(işLEM HACMi)

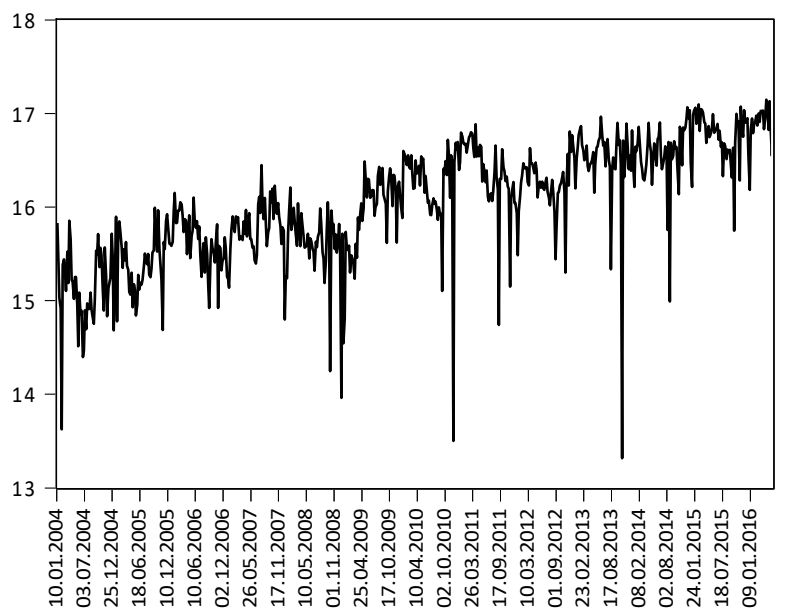

Yatırımcı ilgisi ile BIST100 endeks getirisi ve işlem hacmi arasındaki nedensellik ilişkisi ilk olarak geleneksel Granger nedensellik testi ile araştırılmıştır. Bu amaçla ilk olarak iki değişkenli VAR modeller (yatırımcı ilgisi-endeks getirisi ve yatırımcı ilgisi-işlem hacmi olmak üzere) tahmin edilmiş ve en uygun gecikme sayısı model seçim kriterleri (Akaike bilgi kriteri) ve VAR modele ait varsayımsal testler dikkate alınarak belirlenmiştir. Buna göre, yatırımcı ilgisi-endeks getirisi için en uygun gecikme sayısı 3, yatırımcı ilgisi-işlem hacmi için en uygun gecikme sayısı 10 olarak belirlenmiştir. Tablo 2'de VAR modellerden elde edilen hata terimleri için otokorelasyon, değişen varyans ve normal dağılım test sonuçları yer almaktadır. Tablo 2 'deki sonuçlara göre, her iki model için hata terimleri otokorelasyonsuz olmakla birlikte, hata terimleri normal dağılmamakta ve sabit varyans varsayımını sağlamamaktadır. 
T. Korkmaz - E. I. Cevik - N. K. Cevik

Tablo 2. VAR Modeller için Varsayımsal Test Sonuçları

\begin{tabular}{l|l|l|l}
\hline VAR Model & LM Otokorelasyon Testi & White Değişen Varyans Testi & JB Normallik Testi \\
\hline BiST-LYi & $5.128[0.274]$ & $267.992[0.000]$ & $1377.226[0.000]$ \\
\hline LiH - LYi & $1.826[0.767]$ & $1111.237[0.000]$ & $11816.27[0.000]$ \\
\hline
\end{tabular}

Not: Parantez içindeki değerler sıfır hipotezi reddedebilmek için olasılık değerini göstermektedir.

Tablo 3'te değişkenler arasındaki Granger nedensellik testi sonuçları yer almaktadır. Tablo 3'teki sonuçlara göre, yatırımcı ilgisinden endeks getirisi ve işlem hacmine yönelik bir nedensellik ilişkisi bulunmazken, endeks getirisi ile işlem hacmi yatırımcı ilgisinin Granger nedeni olarak belirlenmiştir. Bu sonuç BIST-100 endeks getirisi ya da işlem hacmindeki değişimlerin (artş ya da azalışlar) yatırımcı ilgisini arttırarak, Borsa İstanbul'un internette aranma sıklığını etkilediğini göstermektedir. Bu sonuçlar literatürde yer alan sonuçlar farklıdır çünkü literatürde gelişmiş ülke piyasaları üzerine yapılan çalışmalarda genellikle yatırımcı ilgisinden piyasaya yönelik bir nedensellik ilişkisi belirlenmiştir.

Tablo 3. Granger Nedensellik Testi Sonuçları

\begin{tabular}{|c|c|c|c|}
\hline Nedenselliğin Yönü & $\begin{array}{l}\text { Gecikme } \\
\text { Uzunluğu }\end{array}$ & $x^{2}$ & p-değeri \\
\hline $\begin{array}{l}L Y I \rightarrow B I S T \\
B I S T \rightarrow L Y I\end{array}$ & $\begin{array}{l}3 \\
3\end{array}$ & $\begin{array}{c}2.704 \\
11.402\end{array}$ & $\begin{array}{l}0.439 \\
0.009\end{array}$ \\
\hline $\begin{array}{l}L Y i \rightarrow L i H \\
L i H \rightarrow L Y i\end{array}$ & $\begin{array}{l}10 \\
10\end{array}$ & $\begin{array}{l}12.617 \\
19.758\end{array}$ & $\begin{array}{l}0.245 \\
0.031\end{array}$ \\
\hline
\end{tabular}

Nedenselliğin yönünü belirlemek amacıyla etki-tepki analizi yapılmış ve sonuçlar Şekil 2'de gösterilmiştir. Şekil 2' deki sonuçlara göre, yatırımcı ilgisinde ortaya çıkacak beklenmedik bir şoka (ani bir artış) endeks getirisi ve işlem hacminin tepkisi istatistiksel olarak anlamlı bulunamamıştır. Diğer taraftan, endeks getirisinde beklenmedik bir artş ortaya çıktı̆ında yatırımcı ilgisinin tepkisi negatif ve istatistiksel olarak anlamlı iken, işlem hacminde beklenmedik bir artşıın yatırımcı ilgisi üzerindeki etkisi pozitif ve istatistiksel olarak anlamlı bulunmuştur.

Bu sonuçlar oldukça ilgi çekicidir, çünkü BIST-100 endeksinde meydana gelecek beklenmedik bir arţş, yatırımcı ilgisini azaltıcı yönde etki yapmakta ve bu durum yatırımcıların piyasada fiyatlar düşme eğiliminde olduğunda daha fazla internet araması yaptığını göstermektedir. Diğer bir ifadeyle, piyasada fiyatlar beklenmedik bir şekilde arttğında yatırımcıların genelde pozisyonlarını koruma yönünde bir eğilim göstererek piyasa için fazladan internette arama yapma gereksinimi duymadığını, fiyatların beklenmedik bir şekilde azaldığında ise yatırımcıların pozisyon değişikliği için piyasaya yönelik internette arama sıklığını arttırdığını göstermektedir. Bu sonuç aynı zamanda davranışsal finansın ileri sürdüğü kötü haberlerin iyi haberlere göre yatıımcılar tarafindan daha çok dikkate alındığı varsayımını da desteklemektedir. İşlem hacminde meydana gelecek beklenmedik bir artı̧̧ı yatırımcı ilgisini arttğı belirlenmiş ve bu sonuç işlem hacminden internette arama sıklığına yönelik bir bilgi akışının varlığına işaret etmektedir.

Borsadaki işlem hacmi piyasanın yönünü tespit etmek için kullanılan önemli bir ölçüttür. Bilindiği gibi teknik analistler, işlem hacmindeki değişmeleri, fiyat değişmeleri için öncü bir gösterge olarak kabul ederler. Çünkü onlara göre fiyatlar artarken işlem hacmi de artar. Öte yandan, fiyatlar düşerken işlem hacmi de azalır. Ancak, işlem hacmi, genel olarak pay fiyat endeksinin düşme eğilimine girmesinden daha önce azalmaya başlar. Ayrıca, fiyat düzeyi en alt noktaya ulaşmadan önce yükselme söz konusu olur (Korkmaz ve Ceylan, 2015: 271). 
Şekil 2. Etki-Tepki Analizi Sonuçları

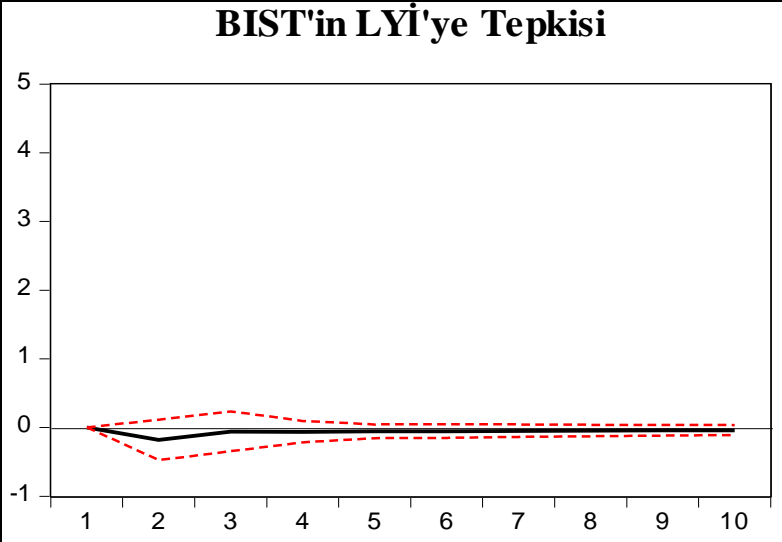

LİH'nin LYI'ye Tepkisi

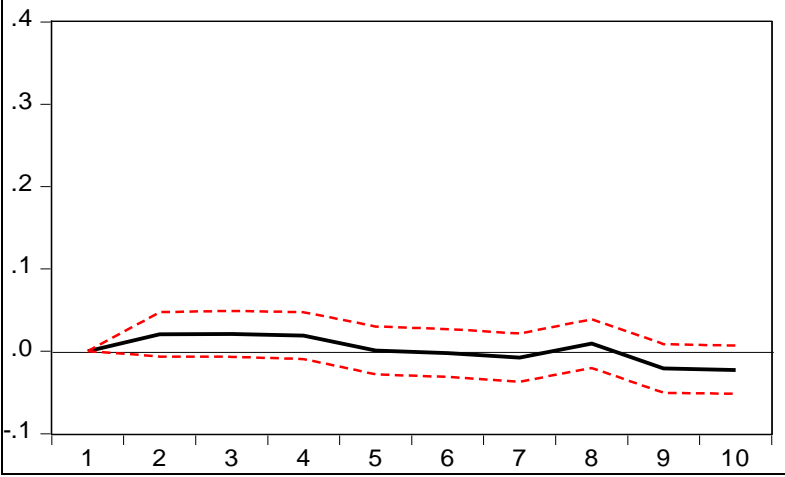

LYI'nin BIST'e Tepkisi

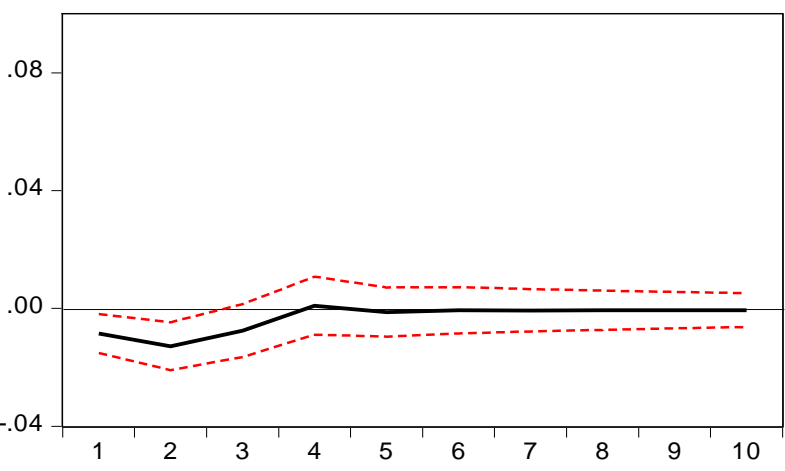

LYI'in LïH'ye Tepkisi

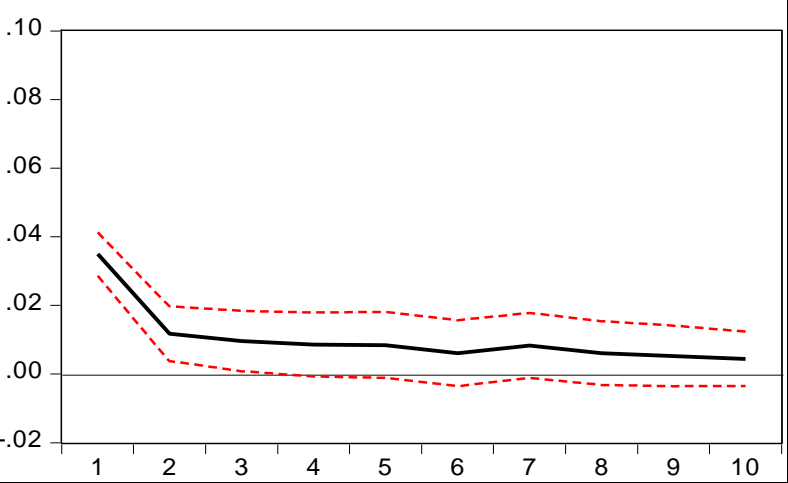

Not: Kesikli çizgiler 2 standart sapmalık güven aralıklarını göstermektedir.

Tablo 4. ARMA-(E)GARCH Model Sonuçları

\begin{tabular}{|c|c|c|c|}
\hline & $L Y i$ & BIST & LiH \\
\hline $\boldsymbol{\mu}$ & $3.938[0.000]$ & $0.370[0.008]$ & $17199[0.000]$ \\
\hline$A R(1)$ & $0.146[0.326]$ & - & $1.406[0.000]$ \\
\hline$A R(2)$ & $0.741[0.000]$ & - & $-0.409[0.000]$ \\
\hline $\mathrm{MA}(1)$ & $0.501[0.000]$ & - & $-0.813[0.000]$ \\
\hline $\mathrm{MA}(2)$ & $-0.257[0.000]$ & - & - \\
\hline$\omega$ & $0.001[0.006]$ & $0.294[0.050]$ & $0.054[0.000]$ \\
\hline$\alpha$ & $0.238[0.000]$ & $0.095[0.132]$ & $0.289[0.020]$ \\
\hline$B$ & $0.605[0.000]$ & $0854[0.000]$ & $0.173[0.298]$ \\
\hline $\boldsymbol{r}$ & - & $-0.127[0.004]$ & - \\
\hline v & $1.106[0.000]$ & $1.611[0.000]$ & $0.836[0.000]$ \\
\hline$\alpha+b$ & 0.843 & 0.949 & 0.462 \\
\hline $\operatorname{Ln}(L)$ & 760.994 & -1743.728 & -57.263 \\
\hline$Q(30)$ & $30.917[0.231]$ & $24.742[0.737]$ & $48.001[0.011]$ \\
\hline Qs (30) & $35.755[0.149]$ & $48.363[0.018]$ & $14.221[0.993]$ \\
\hline
\end{tabular}

Not: Köşeli parantez içindeki değerler p-değerleridir. v Genelleştirilmiş Hata Dağılımı (GED) parametresini ve Ln(L) modelin En Yüksek Olabilirlik değerini göstermektedir. $Q(30)$ ve $Q_{s}(30)$ hata terimleri ve hata terimlerinin kareleri için Ljung-Box otokorelasyon test sonuçlarını göstermektedir 
Burada dikkat edilmesi gereken bir diğer nokta, Tablo 3'teki sonuçlara göre, VAR modellerden elde edilen hata terimlerinin normal dağılmadı ve değişen varyans özelliği gösterdiğidir. Bu nedenle VAR modelin tahminine dayanan nedensellik analizleri sapmalı sonuçlar üretebilmekte çünkü nedensellik testinde kullanılan test istatistiğinin asimptotik olarak $\chi^{2}$ dağılımına sahip olduğu varsayılmaktadır. Bununla birlikte hata terimlerinin normal dağılıma sahip olmaması ve değişen varyans özelliği göstermesi durumunda test istatistiği de asimptotik olarak $\chi^{2}$ dağılımına sahip olmayacaktır. Bu nedenle çalışmada Hong (2001) tarafindan geliştirilen nedensellik testi uygulanmıştr.

Hong (2001) nedensellik testinin ilk aşaması serilerin GARCH model ile tahmin edilmesidir. Bu amaçla, endeks getirisi için EGARCH model, yatrımcı ilgisi ve işlem hacmi serileri için GARCH model tahmin edilmiş ve sonuçlar Tablo 4'de gösterilmiştir. Ortalama denklemi için en uygun AR ve MA süreci Akaike bilgi kriterine göre belirlemiştir. Tablo 4'deki sonuçlara göre, endeks getiri serisi için $v$ parametresi negatif ve istatistiksel olarak anlamlı bulunmuş ve sonuç oynaklıkta kaldıraç etkisinin varlığına işaret etmektedir.

Testin ikinci aşamasında GARCH modellerden standardize edilmiş hata terimleri elde edilmiş ve bu hata terimleri için çapraz korelasyon fonksiyonu hesaplanarak test istatistikleri belirlenmiştir. Bu bilgiler ışı̆̆ında, Tablo 5'de ortalamada nedensellik testi sonuçları yer almaktadır. Nedensellik testi hesaplanırken beş gecikme dikkate alınmış ve test sonuçları endeks getirisi ile yatırımcı ilgisi arasında bir nedensellik ilişkisi olmadığına işaret ederken, işlem hacmi ile yatırımcı ilgisi arasında işlem hacminden yatırımcı ilgisine doğru bir nedensellik ilişkisinin olduğunu göstermektedir.

Tablo 5. Hong (2001) Ortalamada Nedensellik Testi Sonuçları

\begin{tabular}{|c|c|c|c|c|c|}
\hline \multirow{2}{*}{ Nedenselliğin Yönü } & \multicolumn{5}{|c|}{ Gecikme Uzunluğu } \\
\hline & $M=1$ & $M=2$ & $M=3$ & $M=4$ & $M=5$ \\
\hline$L Y I \rightarrow B I S T$ & -0.369 & -0.423 & -0.346 & -0.236 & -0.175 \\
\hline$B I S T \rightarrow L Y i$ & 1.067 & 0.884 & 0.786 & 0.737 & 0.686 \\
\hline$L Y i \rightarrow L i H$ & -0.478 & -0.612 & -0.672 & -0.596 & -0.468 \\
\hline$L i H \rightarrow L Y i$ & $4.615^{* * *}$ & $4.372 * * *$ & $4.032 * * *$ & $3.704^{* * *}$ & $3.409 * * *$ \\
\hline
\end{tabular}

Not: ${ }^{* * *}$ işareti \%1 anlamlılık düzeyinde nedensellik ilişkisini göstermektedir.

Tablo 6 'da ise GARCH modellerinden elde edilen standardize hataların kareleri kullanılarak hesaplanan varyansta nedensellik testi sonuçları yer almaktadır. Bu sonuçlara göre, beşinci gecikmede ve \%10 önem düzeyinde yatırımcı ilgisinden endeks getirisine yönelik varyansta nedensellik ilişkisi belirlenmiş̧tir. Bu sonuç, Borsa İstanbul'un internette aranma sıklığındaki değişkenliğin artmasının pay piyasasında oynaklığın artmasına neden olduğunu göstermektedir. Diğer taraftan işlem hacminden yatırımcı ilgisine yönelik nedensellik ilişkisi varyansta nedensellik testine göre önemini korumaktadır ve işlem hacmindeki değişkenliğin artması yatırımcı ilgisindeki değişkenliğin artmasına neden olmaktadır.

Tablo 6. Hong (2001) Varyansta Nedensellik Testi Sonuçları

\begin{tabular}{|c|c|c|c|c|c|}
\hline \multirow{2}{*}{ Nedenselliğin Yönü } & \multicolumn{5}{|c|}{ Gecikme Uzunluğu } \\
\hline & $M=1$ & $M=2$ & $M=3$ & $M=4$ & $M=5$ \\
\hline$L Y I \rightarrow B I S T$ & -0.115 & -0.280 & 0.314 & 1.004 & $1.433^{*}$ \\
\hline$B I S T \rightarrow L Y i$ & 0.868 & 0.876 & 0.794 & 0.684 & 0.568 \\
\hline $\begin{array}{l}L Y i \rightarrow L i H \\
L i H \rightarrow L Y i\end{array}$ & $\begin{array}{c}-0.508 \\
3.710 * * *\end{array}$ & $\begin{array}{c}-0.663 \\
3.502 * * *\end{array}$ & $\begin{array}{c}-0.816 \\
3.161 * * *\end{array}$ & $\begin{array}{c}-0.951 \\
2.858 * * *\end{array}$ & $\begin{array}{c}-1.068 \\
2.605^{* * *}\end{array}$ \\
\hline
\end{tabular}

Not: *** ve * işareti serinin \%1 ve \%10 önem düzeyinde nedensellik ilişkisini göstermektedir.

\section{Sonuç}

Yatırımcıların yatırım kararı alma sürecinde gerek piyasa gerekse firmaya yönelik bilgileri dikkate aldıkları bilinmektedir. Yatırımcı ilgisi direk olarak gözlenememekte ve bu nedenle literatürde yatırımcı ilgisini ölçebilmek için farklı temsili değişkenler kullanılmaktadır. Özellikle son yıllarda finans literatüründe yatıımcı ilgisinin ölçülmesinde internette aranma sıklığının temsili bir değişken olarak kullanıldığı görülmektedir. Bu 
çalışmada Borsa İstanbul özelinde, Borsa İstanbul ile ilgili kelimelerin internette aranma sıklığı ile getiri ve işlem hacmi arasında bir ilişki olup olmadığı nedensellik testleri ile araştrıımıştır.

Çalışmada ilk olarak yatırımcı ilgisi ile BIST-100 endeks getirisi ve işlem hacmi arasındaki ilişki VAR modele dayanan Granger nedensellik testi ve etki-tepki fonksiyonları ile araştırılmıştır. Gerek nedensellik testi gerekse etki-tepki fonksiyonu sonuçları endeks getirisi ve işlem hacminden yatıımcı ilgisine yönelik bir ilişki olduğunu göstermektedir. Özellikle yatırımcı ilgisinin endeks getirisindeki beklenmedik artşlara ters yönlü tepki vermesi yatırımcılarının endeksin düşme eğiliminde olduğu dönemlerde daha fazla bilgiye gereksinim duyduklarını göstermektedir. VAR modelden elde edilen hata terimlerinin varsayımları sağlamaması nedeniyle Hong (2001) tarafindan geliştirilen test yöntemi ayrıca uygulanmış ve test sonuçları işlem hacminden yatıımcı ilgisine yönelik ortalama ve varyansta nedensellik ilişkisi olduğunu göstermektedir. Buna göre, pay piyasasında işlem hacminin artması piyasasının internette aranma sıklığını etkileyen önemli bir faktör olduğu sonucuna varılmıştır. İşlem hacminin piyasasının yönünü gösteren öncü bir gösterge olduğu dikkate alındığında, BisT’teki yatırımcıların piyasadaki değişimlere göre piyasaya yönelik bilgi talebinde bulunduğu sonucu ortaya çıkmaktadır.

Bu çalışmadan elde edilen sonuçlar, hem kuramsal teorilerin geçerliliğinin test edilmesi açısından hem de ulusal ve uluslararası yatırımcılar açısından önemlidir. Finans ile ilgili kuramsal teorilerde (etkin piyasa hipotezi, sermaye varlıkları fiyatlama modeli, karışık dağılım hipotezi gibi) yer alan bilginin önemi Borsa İstanbul açısından araştrıımıştır. Bu bağlamda pay piyasasına yönelik bilgi talebinin artması durumunda piyasadaki fiyatlama mekanizmasının ne şekilde değiştiğini anlamamıza yardımcı olacaktır. Özellikle yatırımcı ilgisini belirten internette aranma sıklı̆ı̆ Google Arama Trendleri tarafindan ücretsiz bir şekilde ve eşanlı temin edilebildiğinden küçük yatırımcılar aranma sıklığı verilerini kontrol ederek yatırım tercihlerini belirleyebilirler.

\section{Son Notlar}

1. Bu çalışma 2-4 Haziran 2016 tarihlerinde Sivas'ta düzenlenen 17. Uluslararası Ekonometri, Yöneylem ve İstatistik Sempozyumunda tebliğ olarak sunulmuştur.

2. http://www.internetworldstats.com/euro/tr.htm

3. http://gs.statcounter.com

4. Serilerin oynaklığında kaldıraç etkisinin varlığı Nelson (1991) tarafindan gelişstirilen EGARCH model ile araştrılmış fakat EGARCH model GARCH modele göre daha üstün sonuç vermemiştir.

5. GAT'da yapılan aramalar Borsa istanbul'un kurumsal yapısındaki değişiklikleri takip etmek gibi farklı nedenlerden dolayı gerçekleşebilir. Bununla birlikte, Borsa Istanbul'un kurumsal yapısındaki değişikliğin araştırılması yine yatıımcı ilgisine işaret etmektedir.

\section{Kaynaklar}

Aouadi, A., Arouri, M., \& Teulon, F. (2013). Investor attention and stock market activity: Evidence from France. Economic Modelling, 35, 674-681.

Bank, M., Larch, M., \& Peter, G. (2011). Google search volume and its influence on liquidity and returns of German stocks. Financial Markets and Portfolio Management, 253, 239-264.

Barber, B. M., \& Odean, T. (2008). All that glitters: The effect of attention and news on the buying behavior of individual and institutional investors. Review of Financial Studies, 21, 785-818.

Beer, F., Hervé, F., \& Zouaoui, M. (2012). Is big brother watching us? Google, investor sentiment and the stock market. http://papers.ssrn.com/abstract=2185979 (Erişim tarihi: 15 Ağustos 2014).

Bollerslev, T. (1986). Generalized autoregressive conditional heteroskedasticity. Journal of Econometrics, 31, 307-327.

Chemmanur, T. \& Yan, A. (2009). Advertising, attention, and stock returns. http://papers.ssrn.com/sol3/papers.cfm?abstract_id=1340605 (Erişim tarihi: 15 Ağustos 2014).

Cheung, Y.W., \& Ng, L.K. (1996). A causality-in-variance test and its application to financial market prices. Journal of Econometrics, 72, 33-48. 
Da, Z., Engelberg, J. \& Gao, P. (2011). In search of attention. The Journal of Finance, 665, 1461-1499.

Dellavigna, S., \& Pollet, J. M. (2009). Investor inattention and Friday earnings announcements. The Journal of Finance, 64, 709-749.

Dzielinski, M. (2012). Measuring economic uncertainty and its impact on the stock market. Finance Research Letters, 93, 167-175.

Fama, E. F. (1970). Efficient capital markets: A review of theory and empirical work. The Journal of Finance, 25, 383-417.

Fehle, F., Tsyplakov, S., \& Zdorovtsov, V. (2005). Can companies influence investor behavior through advertising? Super Bowl commercials and stock returns. European Financial Management, 11, 625-647.

Gervais, S., Kaniel, R., \& Mingelgrin, D. H. (2001). The high-volume return premium. The Journal of Finance, 56, 877919.

Grullon, G., Kanatas, G., \& Weston, P.J. (2004). Advertising, breath of ownership, and liquidity. Review Financial Studies, $17,439-461$.

Henriques, I., \& Sadorsky, P. (2008). Oil price and the stock price of alternative energy companies. Energy Economics, 30, 998-1010.

Hong, Y. (2001). A test for volatility spillover with application to exchange rates. Journal of Econometrics, 103, $183-224$.

Hou, K., Peng, L., \& Xiong, W. (2008). A tale of two anomalies: The implications of investor attention for price and earnings momentum. http://papers.ssrn.com/sol3/ papers.cfm?abstract_id=976394 (Erişim tarihi: 15 Ağustos 2014).

Joseph, K., Babajide Wintoki, M. \& Zhang, Z. (2011). Forecasting abnormal stock returns and trading volume using investor sentiment: Evidence from online search. International Journal of Forecasting, 274, 1116-1127.

Kahneman, D. (1973). Attention and effort, Prentice-Hall, Englewood Cliffs, NJ.

Korkmaz, T., \& Ceylan, A. (2015). Sermaye piyasası ve menkul değer analizi, 7. Baskı, Ekin Kitabevi, Bursa.

Latoeiro, P., Ramos, S. B., \& Veiga, H. (2013). Predictability of stock market activity using Google search queries. http://earchivo.uc3m.es/handle/10016/16514, (Erişim Tarihi: 15 Ağustos 2014).

Liu, Y., Lv, B., Peng, G., \& Zhang, C. (2012). Relationship between internet search data and stock return: Empirical evidence from Chinese Stock Market. Recent Progress in Data Engineering and Internet Technology, 25-30.

Lou, D. (2008). Attracting investor attention through advertising. http://www.Ise.ac.uk/fmg/workingPapers/discussionPapers/DP644_2009_AttractingInvestorAttention.pdf (Erişim tarihi: 15 Ağustos 2014).

Mantalos, P., \& Shukur, G. (2010). The effect of spillover on the Granger causality test. Journal of Applied Statistics, 37 , 1473-1486.

Merton, R. C. (1987). A simple model of capital market equilibrium with incomplete information. The Journal of Finance, 42, 483-510.

Mondria, J., Wu, T., \& Zhang, Y. (2010). The determinants of international investment and attention allocation: Using internet search query data. Journal of International Economics, 821, 85-95.

Nelson, D. B. (1991). Conditional heteroskedasticity in asset returns: A new approach. Econometrica, 59 (2), $347-370$.

Seasholes, M. S., \& Wu, G. (2007). Predictable behavior, profits, and attention. Journal of Empirical Finance, 14, 590610.

Smith, G. P. (2012). Google Internet search activity and volatility prediction in the market for foreign currency. Finance Research Letters, 92, 103-110.

Takeda, F. \& Wakao, T. (2014). Google search intensity and its relationship with returns and trading volume of Japanese stocks. Pacific-Basin Finance Journal, 27, 1-18.

Takeda, F., \& Yamazaki, H. (2006). Stock price reactions to public TV programs on listed Japanese companies. Economics Bulletin, 137, 1-7.

Tarı, R. (2006). Ekonometri. Avcı Ofset, İstanbul.

Yuan, Y. (2008). Attention and trading. http://course.shufe.edu.cn/jpkc/jcjx/zyff/doc/tl01.pdf (Erişim tarihi: 15 Ağustos 2014). 
This Page Intentionally Left Blank 